\title{
DERECHO Y POLÍTICAS AMBIENTALES EN LA COMUNIDAD DE MADRID (SEGUNDO SEMESTRE 2021)
}

\author{
DANIEL B. ENTRENA RUIZ \\ Profesor Contratado Doctor \\ Universidad Carlos III de Madrid ${ }^{1}$
}

\begin{abstract}
SUMARIO: 1. Acuerdo de 21 de abril de 2021, del Consejo de Gobierno, por el que se aprueban las normas reguladoras y se establece el procedimiento de concesión directa de incentivos para el fomento de la movilidad cero emisiones en la Comunidad de Madrid. 2. Orden 899/2021, de 29 de abril, de la Consejería de Medio Ambiente, Ordenación del Territorio y Sostenibilidad, por la que se dictan instrucciones generales sobre la innecesariedad de someter algunas actuaciones a calificación urbanística con el fin de agilizar y facilitar la implantación de actividades propias del medio rural. 3. Acuerdo del Pleno, de 5 de octubre de 2018, por el que se aprueba la Ordenanza de Movilidad Sostenible del Ayuntamiento de Madrid.
\end{abstract}

1. ACUERDO DE 21 DE ABRIL DE 2021, DEL CONSEJO DE GOBIERNO, POR EL QUE SE APRUEBAN LAS NORMAS REGULADORAS Y SE ESTABLECE EL PROCEDIMIENTO DE CONCESIÓN DIRECTA DE INCENTIVOS PARA EL FOMENTO DE LA MOVILIDAD CERO EMISIONES EN LA COMUNIDAD DE MADRID

Según indica la Exposición de Motivos del Acuerdo que comentamos, el 55,7\% de los ciudadanos ocupados de la Comunidad de Madrid desarrolla su actividad profesional en el mismo municipio de residencia, mientras que el $44,3 \%$ restante debe desplazarse a otros municipios; a esta movilidad se añade la resultante de traslados por estudios, compras y otras actividades cotidianas de los ciudadanos.

Todo ello origina que en la Comunidad de Madrid se realicen 15,8 millones de desplazamientos diarios, lo que supone una ratio de 2,44 viajes por persona.

\footnotetext{
${ }^{1}$ Open Researcher and Contributor ID (ORCID): 0000-0003-1393-0736
} 
Estos impresionantes datos, junto a los efectos de la calidad de la atmósfera que esos desplazamientos, justifican en origen este Acuerdo cuya finalidad es en términos generales incentiva la movilidad sostenible y ya estrictamente subvencionar la adquisición de vehículos eléctrico tanto por personas físicas como autónomos y microempresas.

Las subvencionas se otorgan de forma directa, esto es, sin convocatoria pública, al amparo del artículo 4.5.c) de la Ley 2/1995, de 8 de marzo, de Subvenciones de la Comunidad de Madrid, que permite dicha forma de adjudicación excepcionalmente, cuando concurran "razones de interés público, social, económico o humanitario, u otras debidamente justificadas".

Los vehículos cuya adquisición es fomentada por estas ayudas son patinetes eléctricos (ayuda de hasta 150 euros), bicicleta de pedales con pedaleo asistido (hasta 600 euros, y que su precio no supere los 4.000 euros -excluidos impuestos y accesorios), ciclomotores eléctricos y motocicletas eléctricas (hasta 700 y 1000 euros respectivamente); además, también pueden ser destinadas a la obtención de bonos ambientales para el uso de los servicios de movilidad compartida (carsharing y motosharing) cero emisiones por el achatarramiento de turismos (categoría M1) sin distintivo ambiental de la Dirección General de Tráfico o con una antigüedad superior a diez años (equivalentes a 1.250 euros como máximo a gastar en periodo no superior a 24 meses).

Sin embargo, quedan fuera de las ayudas contempladas los vehículos concebidos para competición, monociclos eléctricos, hoverboards, monopatines eléctricos, segways y similares, así como de segunda mano.

Las ayudas comprometidas pueden ser obtenidas una única vez por personas físicas y hasta cinco vehículos autónomos y microempresas, durante el periodo de ejecución del Programa, esto es, hasta el 31 de diciembre de 2023. Su obtención queda condicionada a la presentación de solicitud previa vía Registro administrativo en el plazo de 3 meses desde la adquisición del vehículo correspondiente. No obstante, la gestión de las ayudas le corresponde a entidades concertadas, con las que consigna contrato público de servicios públicos la propia Comunidad de Madrid. 
2. ORDEN 899/2021, DE 29 DE ABRIL, DE LA CONSEJERÍA DE MEDIO AMBIENTE, ORDENACIÓN DEL TERRITORIO Y SOSTENIBILIDAD, POR LA QUE SE DICTAN INSTRUCCIONES GENERALES SOBRE LA INNECESARIEDAD DE SOMETER ALGUNAS ACTUACIONES A CALIFICACIÓN URBANÍSTICA CON EL FIN DE AGILIZAR Y FACILITAR LA IMPLANTACIÓN DE ACTIVIDADES PROPIAS DEL MEDIO RURAL.

La Ley 9/2001, de 17 de julio, del Suelo de la Comunidad de Madrid contempla la calificación urbanística mecanismo de intervención de la Administración autonómica en el mercado inmobiliario, con el objeto específico completar las determinaciones urbanísticas y autorizar las actuaciones edificatorias y sobre usos del suelo no urbanizable de protección y en el suelo urbanizable no sectorizado, sin perjuicio de la necesidad de obtener la correspondiente licencia urbanística municipal (artículos 147 y ss).

La Orden que comentamos establece que algunas actuaciones no exigen calificación urbanística previamente, entre otros: La instalación de invernaderos temporales, desmontables, portátiles y sin cimentación o la instalación de comederos abrevaderos desmontables, portátiles y sin cimentación (si no hay otras construcciones en la finca), pero también los cerramientos perimetrales de fincas o parcelas, o "la instalación de carpas temporales para eventos sin solera".

Cabe así preguntarse si entre esas actividades, que se desarrollan bajo carpas sin solera se encuentran, por ejemplo, la celebración de eventos sociales en fincas rústicas.

Y nos tememos que la respuesta es positiva.

La Ley 9/2001, de 17 de julio de la Comunidad de Madrid permite el uso en suelo no urbanizable de "las actividades que favorezcan el desarrollo rural sostenible..." (art 29), si bien previa calificación urbanística. 
Pues bien, respecto a esta cuestión, la Ley 8/2012, de 28 de diciembre, de Medidas Fiscales y Administrativas, cuyo artículo 9 contempla los "Usos que favorecen el desarrollo rural sostenible", que define como

"los vinculados a la celebración de actos sociales y eventos familiares de especial singularidad, así como los usos caninos y ecuestres, en edificaciones existentes que puedan ser habilitadas a esos exclusivos fines, que se ubiquen en suelo no urbanizable con cualquier protección y suelo urbanizable no sectorizado".

No obstante, según la misma Ley al igual que la Ley urbanística de Madrid, la implantación de estos exige sujeción previa al procedimiento de calificación urbanística y deberán contar en todo caso con la preceptiva licencia municipal.

Sin embargo, la Orden que comentamos deja fuera de este régimen la instalación de carpas sin solera, lo que a buen seguro permite el desarrollo de actos que según por la propia Ley $8 / 2012$, de 28 de junio, favorecen el desarrollo rural sostenible., quedando definitivamente postergada la exigencia de calificación urbanística en estos casos, mediante la Orden comentada, salvo que se interprete que subsiste la sujeción a ese trámite respecto al uso en sí mismo.

Formalmente, la Orden resulta muy discutible dado que, en puridad, está desarrollando la propia Ley del Suelo de la Comunidad de Madrid, estableciendo un régimen jurídico singular para concretas actuaciones que únicamente quedan exoneradas de calificación urbanística autonómica cuando aquella lo permite, por ejemplo, obras e instalaciones y los usos requeridos por los equipamientos, infraestructuras y servicios públicos estatales, autonómicos o locales (artículo 29.2). Sustantivamente, además, la sujeción de esas actuaciones a dicho régimen resulta obligatorio según la propia Ley, que no deja margen respecto a su eventual exigencia por ejemplo en atención a las concretas circunstancias de cada caso, por lo que no debería producirse esa exención general, que solo es posible en esos supuestos expresamente contemplados en ella. 
No deja de ser paradójico que la Orden disponga en su artículo 1 que resulta de aplicación respecto a "actividades propias del medio rural que pueden llevar asociado el empleo de medios técnicos e instalaciones indispensables para el ejercicio de la actividad".

Asistimos en todo caso, a un acto más de apartamiento público deliberado respecto a determinadas actividades en suelo no urbanizable de protección, en línea con la modificación por la Ley $1 / 2020$, de 8 de octubre, para el impulso y reactivación de la actividad urbanística, que modificó la Ley 9/2001, de 17 de julio de la Comunidad de Madrid para sujetar a declaración responsable en lugar de licencia, entre otras actuaciones, los cerramientos de parcelas, obras y solares y la primera ocupación y funcionamiento de edificaciones e instalaciones, por ejemplo de la implantación de carpas para eventos sociales.

\section{ACUERDO DEL PLENO, DE 5 DE OCTUBRE DE 2018, POR EL QUE SE APRUEBA LA ORDENANZA DE MOVILIDAD SOSTENIBLE DEL AYUNTAMIENTO DE MADRID.}

La aprobación de la nueva Ordenanza de Movilidad Sostenible de la ciudad de Madrid debe resaltase, habida cuenta todo el embrollo jurídico que la ha precedido, a partir de la impugnación de la anterior normativa para batir el régimen de protección de la Zona de Bajas Emisiones Madrid Central; como hemos ido relatando la aprobación de la Ordenanza anterior sin informe económico financiero motivó su anulación tras el recurso presentado por el Grupo Municipal del Partido Popular, entonces en la oposición. Con este partido político ya en el Gobierno, el equipo de gobierno se ha visto obligado a presentar una nueva Ordenanza de Movilidad que respondiera a las obligaciones medioambientales en materia de protección de la calidad del aire, pero también al mismo tiempo tratando de cumplir los compromisos electorales de atenuar el rigor de estas limitaciones.

Y ciertamente, han conseguido lo segundo más bien, no así lo primero, porque si bien la norma innova un nuevo régimen denominado Madrid 360, aplicable a toda la ciudad, que limita la entrada de vehículos más contaminantes a toda ella, y crea 
una nueva Zona de Protección Especial en una de las zonas más contaminadas (Plaza Elíptica), contiene una clara regresión en relación con la anterior ZBE Madrid Central, ahora denominada Madrid Distrito Centro, como consecuencia de las múltiples excepciones ligadas tanto a la clasificación de los vehículos que pueden acceder como a la finalidad y razones que las justifican [artículo 23.3.c)].

En el Proyecto se refiere con insistencia que la norma se aprueba en el ejercicio de las competencias municipales propias sobre tráfico, estacionamiento y movilidad que atribuye a los municipios la Ley 7/1985, de 2 de abril, reguladora de las Bases del Régimen Local (LBRL) [art 25.2.g)].

En consonancia con este planteamiento se invoca el Real Decreto Legislativo 6/2015, de 30 de octubre, por el que se aprueba el Texto Refundido de la Ley sobre Tráfico, Circulación de Vehículos a Motor y Seguridad Vial (TRLTSV), el cual efectivamente atribuye a los municipios las competencias mediante agentes propios, de ordenación, gestión, vigilancia y disciplina del tráfico y mediante ordenanza municipal, entre otros aspectos, el cierre de las vías urbanas cuando sea necesario y la restricción por motivos medioambientales (artículo 7 TRLTSV).

La invocación a la competencia municipal en materia de protección contra la contaminación atmosférica [artículo 25.2.b) de la LBRL] es, así, puramente incidental, cuando la realidad es que el objetivo específico de la creación de ZBE es precisamente éste, aunque sea a través de la ordenación y restricción del tráfico.

No hay duda de que el Ayuntamiento de Madrid es competente para la aprobación de la Ordenanza Municipal cuestionada, habida cuenta que tanto en una como en otra materia la legislación atribuye a los municipios competencias propias [artículo 25 2.b) y g) LBRL).

Sin embargo, a nuestro juicio, la Ordenanza puede excederse en los límites trazados para el ejercicio de esas competencias; así, la CE atribuye al Estado la competencia exclusiva, de un lado, sobre tráfico y circulación de los vehículos a motor (art. 149.1.21 CE) y, de otro, para aprobar la legislación básica en materia de medio ambiente (artículo 149.1.23 CE). 
Como es sabido, de conformidad con los artículos 137 y $140 \mathrm{CE}$, la autonomía local se identifica con la capacidad de los EELL para autoadministrar la gestión de sus propios intereses. Sin embargo, al contrario de lo que sucede con las competencias del Estado y de las CCAA, las atribuidas a los EELL no vienen determinadas por la propia $C E$, sino que están contempladas con carácter general en la LBRL, acorde con la función constitucional que le incumbe, y que posteriormente concreta la legislación sectorial (STC 132/2014, de 22 de julio).

Lo anterior significa en el caso que nos atañe que las competencias locales sobre tráfico y medio ambiente serán ejercidas en el marco de la legislación en esas materias, sin perjuicio de la preservación de la autonomía local a través de elementos reconocibles de la institución.

Pues bien, hay un texto normativo respecto al que no existe la más mínima referencia en todo el Proyecto y que resulta capital: la Ley 7/2021, de 20 de mayo, de Cambio Climático y Transición Energética (LCCTE)

El artículo 14 de esta Ley se rubrica "Promoción de movilidad sin emisiones". Pues bien, su apartado tercero obliga a los municipios de más de 50.000 habitantes y territorios insulares a adoptar antes del 2023 Planes de movilidad sostenible que incorporen Zonas de Bajas Emisiones, entendiendo por tal

"el ámbito delimitado por una Administración pública, en ejercicio de sus competencias, dentro de su territorio, de carácter continuo, y en el que se aplican restricciones de acceso, circulación y estacionamiento de vehículos para mejorar la calidad del aire y mitigar las emisiones de gases de efecto invernadero, conforme a la clasificación de los vehículos por su nivel de emisiones de acuerdo con lo establecido en el Reglamento General de Vehículos vigente"

Es precisamente con este precepto con el que choca la Ordenanza, extralimitándose en el ejercicio de las competencias atribuidas en materia de medio ambiente. $Y$ lo hace desde el momento en que permite un régimen específico de excepciones de entrada a las ZBEDEP de Madrid Distrito Centro como de Plaza Elíptica, que no categorizan el acceso, circulación y estacionamiento de vehículos conforme al mencionado Reglamento General de Circulación de Vehículos. 
Así lo afirma expresamente la Ordenanza al referir en su artículo 23.3.c) que la primera de esas ZBEDEP combina en lo relativo al acceso y la circulación, la clasificación de vehículos por su potencial contaminante, conforme al Reglamento General de Vehículos, con la razón de acceso y circulación de los vehículos, lo que permite incorporar toda una serie de excepciones de entrada que no están contempladas en la legislación básica del Estado como criterio específico de acceso a las ZBE. E igualmente acontece en relación con la ZBEDPE Pza. Elíptica (artículo 24.3 del Proyecto).

Desde esta óptica parece posible concluir que la futura OMS puede incurrir en un posible exceso competencial al regular el acceso a las ZBE bajo criterios distintos a la clasificación ambiental de vehículos que es el único criterio permitido por la legislación básica estatal. 